Psychological Medicine, 2001, 31, 189-195. Printed in the United Kingdom

(C) 2001 Cambridge University Press

THEORETICAL PAPER

\title{
A cognitive model of the positive symptoms of psychosis
}

\author{
P. A. GARETY, ${ }^{1}$ E. KUIPERS, D. FOWLER, D. FREEMAN AND P. E. BEBBINGTON \\ From the Academic Department of Psychiatry and Psychology, Guy's, King's and St Thomas's Medical \\ School, King's College London, Department of Psychology, Institute of Psychiatry and Royal Free and \\ University College Medical School, London; and University of East Anglia, Norwich
}

\section{INTRODUCTION}

In the last 10 years a consensus has developed that the symptoms of psychosis may be better understood by linking the steps between the phenomenological experiences and social, psychological and neurobiological levels of explanation. Cognitive models of psychosis are an important link in this chain. They provide a psychological description of the phenomena from which hypotheses concerning causal processes can be derived and tested; social, individual, and neurobiological factors can then be integrated via their impact on these cognitive processes. In this paper, we set out the cognitive processes that we think lead to the formation and maintenance of the positive symptoms of psychosis and we attempt to integrate into our model research in social factors. If this model proves useful, a fuller integration with the findings of biological research will be required (Frith, 1992).

Our cognitive model builds on the work of other researchers (e.g. Maher, 1988; Frith, 1992; Hemsley, 1993; Bentall et al. 1994; Chadwick \& Birchwood, 1994; Morrison et al. 1995) and our own clinical and theoretical studies. The model is new in that it incorporates both disruptions in automatic cognitive processes and maladaptive conscious appraisals; it covers delusions and hallucinations in one framework; it posits a central role for emotion; and it considers how social factors may contribute to the origins,

1 Address for correspondence: Professor P. A. Garety, Academic Department of Psychiatry and Psychology, Guy's, King's and St Thomas's Medical School, King's College London, Adamson Centre for Mental Health, St Thomas's Hospital, Lambeth Palace Road, London SE1 7EH maintenance or recurrence of symptoms. The resulting cognitive model of psychosis is consistent with existing theoretical and therapeutic studies. It generates testable hypotheses and should lead to theoretical and therapeutic advances.

\section{A cognitive model of psychosis}

There is widespread agreement that psychosis occurs in people with a vulnerable predisposition (of biopsychosocial origin); that onset often follows life events, adverse environments, illicit drug use, or periods of isolation; that there are emotional changes, and disruptions in cognitive processes of attention, perception, or judgement; and that, at onset, its most prominent symptoms are delusional beliefs and hallucinations (Garety et al. 2000).

We postulate two proximal routes to the development of the positive symptoms of psychosis: one proceeds through cognitive and affective changes; the other proceeds through affective disturbance alone. We think the first route is the more common: a triggering event gives rise in a predisposed person to a disruption of cognitive processes (Garety \& Hemsley, 1994). The basic automatic cognitive disturbance may be conceptualized in two ways. First, it may be viewed as a 'weakening of the influences of stored memories of regularities of previous input on current perception', which leads to ambiguous, unstructured sensory input and the subsequent intrusion into consciousness of unintended material from memory (Hemsley, 1993). Secondly, the basic cognitive dysfunction may be recently developed difficulties with the self- 
monitoring of intentions and actions, which would lead to individuals' own intentions to act not being recognized and therefore being experienced as alien (Frith, 1992). (There are similarities between these accounts, as Hemsley (1998) has noted. Both imply a breakdown in 'willed intention' activity, particularly in the later stages of the disorder, albeit for different reasons.) What is important for our model is that at onset both accounts emphasize that the basic cognitive disturbance leads to anomalous conscious experiences (e.g. heightened perception, actions experienced as unintended, racing thoughts, thoughts appearing to be broadcast, thoughts experienced as voices, two unconnected events appearing to be causally linked). Many sufferers report of these cognitive and perceptual changes of the psychotic prodrome that they are experienced as unfamiliar and not like ordinary self-generated cognitions - they feel external and potentially threatening. At this point, however, these experiences have not been transformed into psychotic symptoms. Emotional changes also occur, in direct response to the triggering event and in response to the anomalous experiences. The generation of arousal is also implicit in the model of cognitive disturbance proposed by Hemsley (1993). Such emotional changes feed back into the moment-by-moment processing of anomalous experiences and influence their content. For example, if anxiety and depression result from a job loss, and further anxiety directly from the experience of voices, the person's voices may develop a threatening and critical content: 'You're useless, you won't get another job now. We're after you, we've got you marked'.

Furthermore, the anomalous experiences, being puzzling and associated with emotional changes, seem personally significant and trigger a search for explanation as to their cause (Maher, 1988). Here biased conscious appraisal processes are crucial: they contribute to a judgement that these confusing experiences (which feel external in any case) are in fact externally caused. Garety \& Freeman (1999) have reviewed the evidence for biases in cognitive processes and found empirical support for an information gathering cognitive style characterized by jumping to conclusions, externalizing attributional biases, and deficits in understanding social situations and the intentions of others. It is likely that these biased appraisal processes are made worse by negative emotional states (e.g. anxiety, depression, anger).

These immediate processes occur against a conducive social-cognitive background. Inner city birth and rearing appear to be major risk factors for psychosis (Mortensen et al. 1999), and there are also variations in incidence of psychosis in ethnic groups. Bhugra and his colleagues (1997) in particular have argued that these factors are linked to social adversity and deprivation. We suggest that earlier adverse experience, such as social marginalization, childhood loss (Agid et al. 1999), or severe childhood trauma, may create an enduring cognitive vulnerability, characterized by negative schematic models of the self and the world (e.g. beliefs about the self as vulnerable to threat, or about others as dangerous) that facilitate external attributions and low self-esteem.

This would be one plausible reason for the finding of Myhrman et al. (1996) from the 1966 Finland birth cohort that unwanted pregnancies resulted in children with twice the risk of developing schizophrenia. Evidence consistent with a role for negative schemas in the development of psychosis has recently been reported by Van Os (2000). In a large epidemiological study in the Netherlands over 7000 people were screened for symptoms and psychiatric status and followed up for 3 years. Those who subsequently developed psychosis were found more likely to have low self-esteem and depressive schemas. Furthermore, Birchwood et al. (2000), in developing a model of auditory hallucinations, have suggested that a childhood experience of social adversity leads to the development of negative schemas involving social humiliation and subordination, which in turn fuel voices and paranoia.

These pre-existing negative schemas also provide content to the psychotic attribution (Bowins \& Shugar, 1998; Fowler et al. 1998). Thus, a person with religious beliefs about innate wickedness concludes that the external threat is caused by a punishing God. Some triggering events may have attributes that render externalizing appraisals particularly compelling; we have pilot data linking life events categorized as intrusive to first episodes of psychosis characterized by persecutory themes (D. Raune, personal communication). Finally, we suggest 
that social isolation contributes to the acceptance of the psychotic appraisal by reducing access to alternative more normalizing explanations (White et al. 2000).

We argue that people with anomalous quasipsychotic experiences do not develop full-blown psychotic symptoms if they are able to reject the hypothesis of externality, leading to a protective self-correcting decision, e.g. 'I thought I was hearing the voice of God, but more likely my mind is playing tricks'; 'Things look different, somehow, I must be stressed with all that's going on'. It is thus quite possible to have hallucinatory experiences without becoming deluded, as has been reported (Peters et al. 1999). The externalizing appraisal is thus a defining decision. Psychosis is recognized as occurring when the individual appraises experiences as externally caused and personally significant. Such appraisals are formally identified as delusions and hallucinations: e.g. 'I am being poisoned'; 'God is giving me special powers'; 'my voices are coming from persecutors who want to kill me'; 'a transmitter is beaming my thoughts worldwide'.

In a small proportion of cases (e.g. some cases of delusional disorder), it appears there is a second route to psychosis: the triggering event does not appear to cause a basic information processing disruption, leading to anomalous experiences. Here, life events trigger only disturbed affect, which in turn directly activates biased appraisal processes and maladaptive self/other schemas leading to an externalizing appraisal (i.e. the delusion) for the life event or the disturbed affect. In such cases, delusions occur independently of hallucinations and other psychotic symptoms.

Central to our model are the factors responsible for the maintenance/recurrence of the psychotic appraisal. Why does it not correct itself when the evidence for it is not forthcoming? We hypothesize that a number of different factors maintain the psychotic appraisal, as follows.

\section{Reasoning processes}

The biased cognitive processes we think contribute to symptom formation are also likely to contribute to symptom maintenance, since these biases have been found in people with persistent symptoms, but may not be present after recovery
(Garety \& Freeman, 1999). These are: a 'jumping to conclusions' data gathering bias, an externalizing attributional style, and poor social understanding or theory of mind. This abnormal reasoning may in turn be maintained by social isolation. We would also highlight two other factors that have received less experimental attention. First, we have obtained evidence that a lack of belief flexibility (the willingness to consider alternatives to delusional beliefs) is associated with poorer outcome, independent of the severity of the delusion (Garety et al. 1997). Secondly, the normal belief confirmation bias is likely to maintain psychotic beliefs (Maher, 1974). These two factors suggest that delusions are more likely to be maintained in individuals who have a dichotomous thinking style and who cannot tolerate ambiguity.

\section{Dysfunctional schemas and adverse social environments}

There is a growing literature on the poor selfconcept and self-esteem of people with psychosis (e.g. Trower \& Chadwick, 1995; Kinderman \& Bentall, 1996). Freeman et al. (1998) found that self-esteem was poor in many people with psychosis. Close \& Garety (1998) found that hallucinations and delusions that have negative content are associated with negative selfconcepts. Psychotic beliefs may be more firmly held if they are consistent with firmly-held distorted beliefs about the self (e.g. that one is bad), others (e.g. that others are hostile) and the world (e.g. the world is dangerous). Moreover, once formed, the delusion is likely to be considered as further confirmation of the negative beliefs, leading to further strengthening of the delusion.

Low self-esteem almost certainly develops in specific social contexts (Brown et al. 1990; Harris et al. 1990). Aversive social environments, such as living with high expressed emotion families, are a robust predictor of poor outcome (Bebbington \& Kuipers, 1994; Butzlaff \& Hooley, 1998). Mueser et al. (1998) report that the lifetime prevalence of traumatic events among a sample of 275 patients with schizophrenia and bipolar disorder was $98 \%$. We have preliminary evidence, from a consecutive series of 77 first episode in-patients with psychosis, that severe trauma histories are more common in those with symptoms unresponsive to medi- 
cation than in those whose symptoms were responsive (Fowler, 1999) while Doering and colleagues (1998) have found that traumatic experiences and adverse circumstances in childhood were related to relapse and rehospitalization in schizophrenia. Furthermore, as discussed earlier, differences in the incidence of psychosis in the inner city and in certain ethnic groups has been linked to social adversity. It seems likely that social marginalization, difficult or traumatic experiences or unsupportive family environments contribute to the development of negative schemas. We speculate from this literature that early trauma and chronic stress can create dysfunctional negative schemas, which in turn contribute to treatment resistance and a vulnerability to relapse.

3 Emotion (e.g. anxiety, depression, anger, mania) and cognitive processes associated with emotion

Clearly, dysfunctional negative schemas will be closely associated with levels of emotional distress. The presence of emotional distress will also contribute to the maintenance of the psychotic appraisal through other processes. Birchwood and colleagues have demonstrated the importance of depression in psychosis (e.g. see Birchwood \& Iqbal, 1998), They report that residual symptoms of both hallucinations and delusions are more common in depressed people with psychosis and propose that feelings of hopelessness and uncontrollability contribute to symptom maintenance. Consistent with this, hopelessness is a predictor of poor outcome in early schizophrenia (Aguilar et al. 1997). We ourselves have focused on anxiety. We argue that three processes traditionally associated with anxiety disorders may be of particular importance. Information processing biases will provide evidence or substantiation for psychotic beliefs and hence maintain them (e.g. deployment of attention; Freeman et al. 2000). Safetybehaviours will prevent the receipt of disconfirmatory evidence and hence prevent change in psychotic beliefs (Freeman \& Garety, 2000). Meta-cognitive beliefs, such as beliefs concerning the uncontrollability of one's thoughts, will increase the distress caused by psychotic experiences (Freeman \& Garety, 1999). Clinically, it has also long been observed that anxiety triggers hallucinations and increases in delusional thoughts, i.e. affects cognitive processing (Slade, 1972). Finally, the experience of emotion will drive a search for meaning and understanding that is consistent with affectassociated beliefs: for example, anxiety will increase the probability that a threatening explanation is sought and accepted.

\section{The secondary appraisal}

The secondary appraisal of the experience of psychosis itself ('illness perception' or insight). We suggest appraisals of illness influence engagement with treatment and adaptive behaviour. Standard assessments of insight are only modestly correlated with outcome (David, 1998). However, insight is correlated with the 'belief maintenance' subscale of the Maudsley Assessment of Delusions, and improved outcome for delusions in response to CBT is associated with and predicted by changes in the MADS subscale (Garety et al. 1997). Also important are appraisals of the experience of chronic mental illness as stigmatizing and humiliating, appraisals which may influence the development of depression (Birchwood \& Iqbal, 1998). These appraisals probably have some basis in reality, given evidence that significant others readily apply negative labels to people developing first episodes of schizophrenia (Bean et al. 1996).

\section{The cognitive model and psychological treatments}

We think theory and therapy in this area are mutually enhancing. Therapy provides a context for theoretical developments and the empirical investigation of our model, which in turn should clarify the targets of psychological treatment, refine its techniques, and enhance its efficacy.

Two sorts of psychological intervention seem to be effective in diminishing positive symptoms and their re-emergence. These are cognitive behaviour therapy (CBT) and interventions with the families of people with psychosis (FI) (Haddock et al. 1998; Birchwood \& Spencer, 1999; Kuipers et al. 1999). It is unlikely that these work in the same way.

We hypothesize that CBT acts directly on psychological processes (this is after all its aim). In particular, it is most effective in treating psychosis when the key appraisal, of inner 
mental disturbance as externally caused, is reappraised as inner. In traditional terminology, 'good insight' is developed. This new schema is incompatible with its psychotic predecessor. Both symptoms and the risk of relapse are thereby reduced. Therapy achieves this by changing the appraisals and, where possible negative self-schemata, and by compensating for the biased reasoning processes (Fowler et al. 1995). We would also propose that clinical improvements and reduced risks of relapse can still occur when the externalizing psychotic appraisal remains unaltered (i.e. insight remains (poor'), provided some of the hypothesized maintenance factors are changed (e.g. safety behaviours), disrupting the vicious cycle.

Family intervention (FI), in contrast, primarily targets the behaviour of family members. It improves social function (Barrowclough \& Tarrier, 1990) and reduces exacerbations of positive symptoms (Pharoah et al. 1999; Kuipers et al. 1999). We offer competing hypotheses about how it affects the cognitive processing of sufferers.

One possibility is that it operates by reducing environmental stress and improving the associated affect (anxiety or depression). Anomalous experiences would be improved mainly by way of these affective changes. We know that conflictual relationships predict poor outcome in social and psychiatric patholology, and that affirmative ones can improve outcome even in those with persistent emotional damage (Lewis, 1998). People with schizophrenia are well able to perceive criticism in their relatives (Tompson et al. 1995; Scazufca et al. 2000). Such relationships must also affect mood: while critical or intrusive behaviour might increase anxiety and depression, supportive relationships would reduce them.

It is of interest that supportive counselling and befriending had some effect in reducing symptoms in two recent trials of CBT in schizophrenia (Tarrier et al. 1998; Sensky et al. 2000). However, the benefits were limited to the duration of the intervention. There is now evidence from a meta-analysis of 19 randomized controlled trials (reported in Kuipers et al. 1999) that FI also needs to be continued for positive effects to be maintained. This analysis found that for single family therapy, the number needed to treat (NNT) to prevent relapse in the first year of treatment was $6 \cdot 3$; in the second year of treatment this fell to $3 \cdot 9$. Once treatment ended the NNT went back up to $7 \cdot 1$ to prevent relapse, and 20.8 to prevent readmission. Thus, although individual studies have found that treatment effects can continue for as long as 8 years after FI finishes (e.g. Tarrier et al. 1994) this was not confirmed by the meta-analysis. This suggests that both FI and supportive therapies have effects which continue only for as long as therapy is offered. In contrast, evidence is emerging that changes from CBT may continue (and may even be enhanced) when therapy finishes (Kuipers $e t$ al. 1998; Tarrier et al. 1999; Sensky et al. 2000). In families (and possibly also the supportive therapies), it seems likely that therapeutic improvement occurs via the reduction of negative affect through the provision of a less stressful environment, and the improvement of social functioning by appropriate prompting and reinforcement of small changes in behaviour. There might also be improvements in thinking processes (e.g. relative to negative schemas or cognitive flexibility), but these would be secondary to the other changes. Thus, under this hypothesis, the cognitive changes brought about by FI would be less specific than with CBT and the maintenance of effects would be less secure.

The contrasting hypothesis is that FI helps family members to discuss directly with sufferers their psychotic experiences and to provide alternative explanations. FI would then operate through cognitive change like CBT. No evidence currently exists to test between these hypotheses in terms of change in individual affect, schemas or appraisals. The second hypothesis requires that carers effectively perform as therapists, but it seems unlikely that most would have the specific skills to do this without training.

\section{Conclusion}

We have put forward a new cognitive model of the positive symptoms of psychosis. While our model is speculative, we think it has plausibility in the context of what we currently know about the various processes involved in delusional thinking and anomalous experience. Moreover, it integrates much of this information in a way that will contribute to the further expansion of knowledge, and may have important practical benefits for people suffering from psychosis. 
We are grateful to Professor David Hemsley for his helpful comments on an earlier draft of the manuscript.

\section{REFERENCES}

Agid, O., Shapira, B., Zislin, J., Ritsner, M., Hanin, B., Murad, H., Troudart, T., Bloch, M., Heresco-Levy, U. \& Lerer, B. (1999). Environment and vulnerability to major psychiatric illness: a case control study of early parental loss in major depression, bipolar disorder and schizophrenia. Molecular Psychiatry 4, 163-172.

Aguilar, E. J., Haas, G., Manzanera, F. J., Hernandez, J., Gracia, R., Rodado, M. J. \& Kesvanan, M. S. (1997). Hopelessness and firstepisode psychosis: a longitudinal study. Acta Psychiatrica Scandinavica 96, 25-30.

Barrowclough, C. \& Tarrier, N. (1990). Social functioning in schizophrenic patients. I. The effects of expressed emotion and family intervention. Social Psychiatry and Psychiatric Epidemiology 24, 125-129.

Bean, G., Beiser, M., Zhang-Wong, J. \& Tacono, W. (1996) Negative labelling of individuals with first episode schizophrenia: the effect of pre-morbid functioning. Schizophrenia Research 22 , 111-118.

Bebbington, P. E. \& Kuipers, E. (1994). The predictive utility of expressed emotion in schizophrenia: an aggregate analysis. Psychological Medicine 24, 707-718.

Bentall, R. P., Kinderman, P. \& Kaney, S. (1994). The self, attributional processes and abnormal beliefs: towards a model of persecutory delusions. Behaviour Research and Therapy 32, 331-341.

Birchwood, M. \& Iqbal, Z. (1998). Depression and suicidal thinking in psychosis: a cognitive approach. In Outcome and Innovation in Psychological Treatment of Schizophrenia (ed. T. Wykes, N. Tarrier \& S. Lewis), pp. 81-100. Wiley: Chichester.

Birchwood, M. \& Spencer, E. (1999). Psychotherapies for schizophrenia: a review. In Schizophrenia (WPA Series: Evidence and Experience in Psychiatry, Vol. 2) (ed. M. Maj and N. Sartorius), pp. 147-214. Wiley: Chichester.

Birchwood, M., Meaden, A., Trower, P., Gilbert, P. \& Plaistow, J. (2000). The power and omnipotence of voices: subordination and entrapment by voices and by significant others. Psychological Medicine 30, 337-344.

Bhugra, D., Leff, J., Mallett, R., Der, G., Corridan, B. \& Rudge, S. (1997). Incidence and outcome of Schizophrenia in Whites, African-Caribbeans and -Asians in London. Psychological Medicine 27, 791-798.

Bowins, B. \& Shugar, G. (1998). Delusions and self-esteem. Canadian Journal of Psychiatry 43, 154-158.

Brown, G. W., Bifulco, A., Veiel, H. O. F. \& Andrews, B. (1990). Self-esteem and depression. II. Social correlates of self-esteem. Social Psychiatry and Psychiatric Epidemiology 25, 225-234.

Butzlaff, R. L. \& Hooley, J. M. (1998). Expressed emotion and psychiatric relapse: a meta-analysis. Archives of General Psychiatry 55, 547-552.

Chadwick, P. D. J. \& Birchwood, M. J. (1994). The omnipotence of voices: a cognitive approach to hallucinations. British Journal of Psychiatry 164, 190-201.

Close, H. \& Garety, P. A. (1998). Cognitive assessment of voices: further developments in understanding the emotional impact of voices. British Journal of Clinical Psychology 37, 173-188.

David, A. S. (1998). The clinical importance of insight. In Insight and Psychosis (ed. X. F. Amador and A. S. David), pp. 332-351. OUP: New York.

Doering, S., Muller, E., Kopcke, W., Pietzcker, A., Linden, M., Muller, P., Muller-Spahn, F., Tegeler, J. \& Schussler, G. (1998). Predictors of relapse and rehospitalization in schizophrenia and schizoaffective disorder. Schizophrenia Bulletin 24, 87-98.

Fowler, D. (1999). The relationship between trauma and psychosis. Paper presented at Merseyside Psychotherapy Institute, Liverpool, May, 1999.
Fowler, D., Garety, P. A. \& Kuipers, L. (1995). Cognitive Behaviour Therapy for Psychosis: Theory and Practice. Wiley: Chichester.

Fowler, D., Garety, P. \& Kuipers, E. (1998). Understanding the inexplicable: an individually formulated cognitive approach to delusional beliefs. In Cognitive Psychotherapy of Psychotic and Personality Disorders (ed. C. Perris and P. D. McGorry), pp. 129-146. Wiley : Chichester.

Freeman, D. \& Garety, P. A. (1999). Worry, worry processes and dimensions of delusions: an exploratory investigation of a role for anxiety processes in the maintenance of delusional distress. Behavioural and Cognitive Psychotherapy 27, 47-62.

Freeman, D. \& Garety, P. A. (2000). Cognitive therapy for an individual with a long-standing persecutory delusion: incorporating emotional processes into a multi-factorial perspective on delusional beliefs. In From Theory to Practice: A Casebook of Cognitive Therapy for Psychosis (ed. T. Morrison) Wiley: Chichester. (In the press.)

Freeman, D., Garety, P., Fowler, D., Kuipers, E., Dunn, G., Bebbington, P. \& Hadley, C. (1998). The London-East Anglia randomised controlled trial of cognitive behaviour therapy for psychosis IV: self-esteem \& persecutory delusions. British Journal of Clinical Psychology 37, 415-430.

Freeman, D., Garety, P. A. \& Phillips, M. L. (2000). An examination of hypervigilance for external threat in individuals with generalised anxiety disorder and individuals with persecutory delusions using visual scan paths. Quarterly Journal of Experimental Psychology 53A, 549-567.

Frith, C. D. (1992). The Cognitive Neuropsychology of Schizophrenia. LEA: Hove.

Garety, P. A. \& Hemsley, D. R. (1994). Delusions: Investigations into the Psychology of Delusional Reasoning. Oxford University Press: Oxford.

Garety, P. A. \& Freeman, D. (1999). Cognitive approaches to delusions: a critical review of theories and evidence. British Journal of Clinical Psychology 38, 113-154.

Garety, P. A., Fowler, D., Kuipers, E., Freeman, D., Dunn, G., Bebbington, P. E., Hadley, C. \& Jones, S. (1997). The LondonEast Anglia Randomised Controlled Trial of Cognitive Behaviour Therapy for Psychosis II : predictors of outcome. British Journal of Psychiatry 171, 319-327.

Garety, P. A., Fowler, D. \& Kuipers, E. (2000). Cognitivebehavioural therapy for medication-resistant symptoms. Schizophrenia Bulletin 26, 73-86.

Haddock, G., Tarrier, N., Spaulding, W., Yusupoff, L., Kinney, C. \& McCarthy, E. (1998). Individual cognitive behaviour therapy in the treatment of hallucinations and delusions: a review. Clinical Psychology Review 18, 821-828.

Harris, T. O., Brown, G. W. \& Bifulco, A. T. (1990). Depression and situational helplessness/mastery in a sample selected to study childhood parental loss. Journal of Affective Disorders 20, 27-41.

Hemsley, D. R. (1993). A simple (or simplistic?) cognitive model for schizophrenia. Behaviour Research and Therapy 31, 633-645.

Hemsley, D. R. (1998). The disruption of the 'sense of self' in schizophrenia: potential links with disturbances of information processing. British Journal of Medical Psychology 71, 115-124.

Jaspers, K. (1913). General Psychopathology (translated by J. Hoenig and M. W. Hamilton, 1959). Manchester University Press: Manchester.

Kinderman, P. \& Bentall, R. P. (1996). Self-discrepancies and persecutory delusions: evidence for a model of paranoid ideation. Journal of Abnormal Psychology 105, 106-113.

Kuipers, E., Fowler, D., Garety, P. A., Chisholm, D., Freeman, D., Dunn, G., Bebbington, P. E. \& Hadley, C. (1998). The LondonEast Anglia Randomised Controlled Trial of Cognitive Behaviour Therapy for Psychosis III: follow-up and economic evaluation at 18 months. British Journal of Psychiatry 173, 61-68.

Kuipers, E., Bebbington, P., Pilling, S. \& Orbach, G. (1999). Family Intervention in psychosis: who needs it. Epidemiologie e Psichiatria Sociale 8, 169-173.

Lewis, J. M. (1998). For better or worse: interpersonal relationships 
and individual outcome. American Journal of Psychiatry 155, 582-589.

Maher, B. A. (1974). Delusional thinking and perceptual disorder. Journal of Individual Psychology 30, 98-113.

Maher, B. A. (1988). Anomalous experience and delusional thinking: the logic of explanations. In Delusional Beliefs (ed. T. F. Oltmanns and B. A. Maher), pp. 15-33. Wiley: New York.

Morrison, A. P., Haddock, G. \& Tarrier, N. (1995). Intrusive thoughts and auditory hallucinations: a cognitive approach Behavioural and Cognitive Psychotherapy 23, 265-280.

Mortensen, P. B., Pedersen, C. B., Westergaard, T. \& Wohlfahrt, J. (1999). Effects of family history and place and season of birth on the risk of schizophrenia. New England Journal of Medicine 25, 645-647.

Mueser, K. T., Goodman, L. B., Trumbetta, S. L., Rosenberg, S. D., Osher, F. C., Vidaver, R., Auciello, P. \& Foy, D. W. (1998)

Trauma and post traumatic stress disorder in psychosis. Journal of Consulting and Clinical Psychology 66, 493-499.

Myhrman, A., Rantakallio, P., Isohanni, M., Jones, P. \& Partanen, U. (1996). Unwantedness of a pregnancy and schizophrenia in the child. British Journal of Psychiatry 169, 637-640.

Peters, E. R., Joseph, S. A. \& Garety, P. A. (1999). Measurement of delusional ideation in the normal population: introducing the PDI. Schizophrenia Bulletin 25, 553-576.

Pharoah, F. M., Mari, J. J. \& Streiner, D. (1999). Family intervention for schizophrenia (Cochrane Review). Cochrane Library, Issue 2. Update Software: Oxford.

Scazufca, M., Kuipers, E. \& Menezes, P. (2000). Perception of negative emotions in close relatives by patients with schizophrenia. British Journal of Clinical Psychology (in the press).

Sensky, T., Turkington, D., Kingdon, D., Scott, J. L., Scott, J., Siddle, R., O'Carroll, M. \& Barnes, T. R. E. (2000). A randomized controlled trial of cognitive-behavior therapy for persistent symptoms in schizophrenia resistant to medication. Archives of General Psychiatry 57, 165-172.

Slade, P. D. (1972). The effects of systematic desensitization on auditory hallucinations. Behaviour Research and Therapy 10, 85-91.

Tarrier, N., Barrowclough, C., Porceddu, K. \& Fitzpatrick, E. (1994). The Salford Family Intervention Project: relapse rates of schizophrenia at five and eight years. British Journal of Psychiatry 165, 829-832.

Tarrier, N., Yusupoff, L., Kinney, C., McCarthy, E., Gledhill, A., Haddock, G. \& Morris, J. (1998). Randomised controlled trial of intensive cognitive behavioural therapy for patients with chronic schizophrenia. British Medical Journal 317, 303-307.

Tarrier, N., Wittkowski, A., Kinney, C., McCarthy, E., Morris, J. \& Humphreys, L. (1999). Durability of the effects of cognitivebehavioural therapy in the treatment of chronic schizophrenia. British Journal of Psychiatry 174, 500-504.

Tompson, M. C., Goldstein, M. J., Lebell, M. B., Mintz, L. I., Marder, S. R. \& Mintz, J. (1995). Schizophrenic patients' perceptions of their relatives' attitudes. Psychiatry Research 57, 155-167.

Trower, P. \& Chadwick, P. (1995). Pathways to defense of the self: a theory of two types of paranoia. Clinical Psychology: Science and Practice 2, 263-277.

Van Os, J. (2000). If schizophrenia is a delusion, is it a useful one? The Third Paul Janssen Lecture May 2000, Institute of Psychiatry, London.

White, R., Bebbington, P., Pearson, J., Johnson, S. \& Ellis, D. (2000). The social context of insight in schizophrenia. Social Psychiatry and Psychiatric Epidemiology (in the press). 